\title{
The Photoxidative Alteration of Chlorophylls in Methyl Linoleate and Prooxidant Activity of Their Decomposition Products
}

\author{
Yasushi ENDO, Riichiro UsUKI and Takashi KANEDA \\ Department of Food Chemistry, Faculty of Agriculture, \\ Tohoku University, Sendai 980, Japan \\ Received September 28, 1983
}

\begin{abstract}
Methyl linoleate containing chlorophylls and/or pheophytins was exposed to light in the presence of oxygen. The photooxidative reaction of both chlorophylls $a$ and $b$ was first-order, and the reaction rate for chlorophyll $a$ was higher than that for chlorophyll $b$. On the other hand, pheophytins $a$ and $b$ hardly decomposed even after irradiation for $24 \mathrm{hr}$, and retained a green or a brownish-green color. In qualitative analysis of the photooxidation products of chlorophylls $a$ and $b$, no pheophytins or pheophorbides were detected, while green and polar red pigments were observed on a thin layer chromatogram near the spot of chlorophyll and the origin, respectively. These photooxidation compounds also had prooxidant effects as well as did chlorophyll.
\end{abstract}

Chlorophyll (Chl) remaining in plant oils is known to promote the oxidation of oils as a photosensitizer. ${ }^{1,2)}$ Previously we observed that even refined edible oils contained more pheophytins (Phys) than chlorophylls (Chls) ${ }^{3)}$ and that pheophytin (Phy) had photooxidative activities as well as did $\mathrm{Chl}^{4}{ }^{4}$ This observation suggested that the $\mathrm{Chl}$ oxidation products which are expected to exist in plant oils might have prooxidant effects or photooxidative activities. Therefore, we investigated the decomposition pathway of $\mathrm{Chl}$ in oils to estimate the oxidative stabilities of oils.

There have been many papers published ${ }^{5 \sim 8)}$ regarding the decomposition rates and products of Chl in various solvent systems. Jen \& Mackinney ${ }^{9)}$ showed that no Phy was detected in the reaction products of irradiated $\mathrm{Chl}$ solutions in the absence of water. Hynninen et $a l .{ }^{10,11)}$ found that allomerization compounds and traces of Phy were formed during the irradiation of Chl-pyridine solutions.

In several laboratories, the relationship between $\mathrm{Chl}$ decomposition and oil deterioration has also been studied. In one of these studies Chl was oxidized by lipoxygenase in the presence of highly unconjugated fatty acids. ${ }^{12)}$
When bleached by lipoxygenase, Chl is expected to change to colorless low molecular weight compounds without the formation of detectable Phy and pheophorbide (Pho) within short period. ${ }^{13)}$ In addition, some investigators $^{14 \sim 16)}$ reported that $\mathrm{Chl}$ may react with intermeditate compounds of lipid peroxidation and peroxides to be bleached. Thus the mechanism of photodegradation of $\mathrm{Chl}$ in oils has not been completely elucidated. In this experiment, the photodegradation rates of Chl and Phy, and spectroscopic and chromatographic characteristics of $\mathrm{Chl}$ photodecomposition products in methyl linoleate (ML) were investigated in order to clarify the mechanism of $\mathrm{Chl}$ photooxidation.

\section{MATERIALS AND METHODS}

Materials and equipment. Preparation of Chl, Phy, and ML were described in a previous paper. ${ }^{4)}$ For the analysis, peroxide-free diethyl ether and acetone of spectrometric analytical grade were used. Other solvents, of reagent grade purity, were used after distillation.

The fluorometric analysis of $\mathrm{Chl}$ and Phy was performed with a Hitachi Spectrophotofluorometer Model 204 , according to the procedure developed in our laboratory. 
Photooxidation of chlorophylls and pheophytins. ML $(1.00 \mathrm{~g})$ containing $2.2 \times 10^{-7} \mathrm{~mol}$ of $\mathrm{Chl}$ or Phy was put in a glass beaker $(27 \mathrm{~mm} \phi)$, and irradiated with transmitted light through the water layer from a $15 \mathrm{~W}$ fluorescent lamp at $0^{\circ} \mathrm{C}$ with occasionally stirring. Light intensity on the surface of the sample was $500 \mu \mathrm{W} / \mathrm{cm}^{2} \mathrm{sec}$. The degradation rates for $\mathrm{Chl}$ and $\mathrm{Phy}$ in $\mathrm{ML}$ were determined by measuring decreased optical density at specific wavelengths (Chl $a, 662$; Chl $b, 646$; Phy $a, 665$; Phy $b, 653 \mathrm{~nm}$ ).

Thin layer chromatography $(T L C)$. A commercial cellulose layer (Funakoshi Chemicals Co., Ltd.; $5 \times 20 \mathrm{~cm}$ ) was used as the plate, which was developed in $n$-heptanepyridine $(7: 3, \mathrm{v} / \mathrm{v})$ under nitrogen gas, in the dark at room temperature. Identification of $\mathrm{Chl}$ derivatives was made by their $R f$ values, color, and the red fluorescence under the UV light. ${ }^{17)}$ For the measurement of visible absorption spectra, ${ }^{18,19)} \mathrm{Chl}$ derivatives were eluted with diethyl ether from the TLC plate.

Prooxidant activities of chlorophyll derivatives. Diethyl ether solutions of $\mathrm{Chl}$ derivatives pooled from TLC plates were added to $\mathrm{ML}$, and irradiated with a fluorescent lamp at $0^{\circ} \mathrm{C}$, as mentioned above. Peroxide values of samples were determined after photooxidation for 12 and $24 \mathrm{hr}$.

\section{RESULTS AND DISCUSSION}

The photodegradation rates of chlorophylls and pheophytins

The photodegradation rates of $\mathrm{Chl}$ and Phy in $\mathrm{ML}$ were determined to estimate their sta-

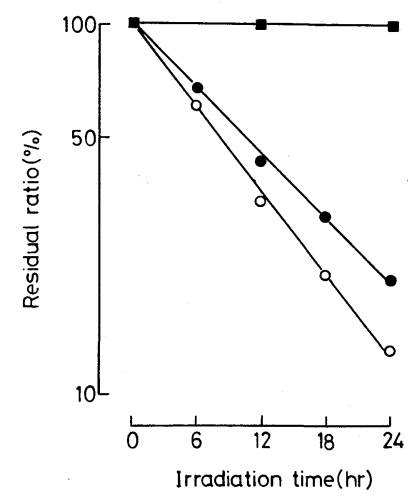

FIG. 1. The Degradation of Chlorophylls and Pheophytins in Methyl Linoleate during Photooxidation.

Chlorophyll or pheophytin $\left(2.2 \times 10^{-7} \mathrm{~mol}\right)$ was added to methyl linoleate $(1.0 \mathrm{~g})$ and irradiated with a fluorescent lamp $\left(500 \mu \mathrm{W} / \mathrm{cm}^{2} \mathrm{sec}\right)$ at $0^{\circ} \mathrm{C}$. Residual ratios were estimated by measuring decreased optical density at the absorption maxima. $\bigcirc, \mathrm{Chl} a ; 0, \mathrm{Chl} b ; \square$, Phy $a$ and $b$. bilities against exposure to light. As shown in Fig. 1, Phys $a$ and $b$ in ML were stable and did not decompose at all during irradiation for $24 \mathrm{hr}$. On the other hand, Chls $a$ and $b$ in ML were very unstable and decomposed readily. The degradative reaction of Chls $a$ and $b$ in ML were found to be first-order and their rate constants were $-8.5 \times 10^{-2}$ and $-6.9 \times 10^{-2}$ $\left(\mathrm{h}^{-1}\right)$ respectively, which indicated a high stability of $\mathrm{Chl} b$ compared to $\mathrm{Chl} a$. We have shown that greater amounts of Phys than Chls were contained in refined edible plant oils by fluorospectrometric analysis. ${ }^{3)}$ These observations agree closely with the data obtained in this experiment. Thus the decomposition products of Chls are expected to exist in commercial plant oils in addition to Chls and Phys.

\section{Changes in visible absorption and fluorescence spectrum}

Changes in the visible absorption spectrum of $\mathrm{Chl}$ during photooxidation in ML are illustrated in Fig. 2. The optical density at the absorption maxima of Chls $a$ and $b$ decreased, while absorption in the blue region of $\mathrm{Chl}$ increased with irradiation time. However, no formation of an absorption maximum for Phy

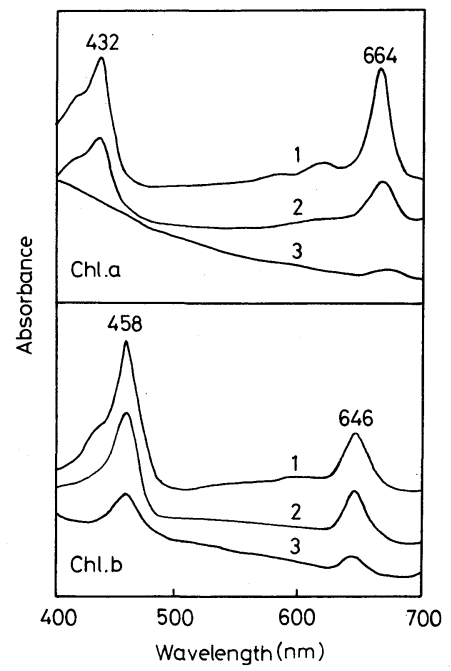

Fig. 2. Changes in Spectra of Chlorophylls $a$ and $b$ in Methyl Linoleate during Photooxidation.

The change in visible absorption spectra of chlorophylls $a$ and $b$ in methyl linoleate was measured after irradiation for (1) $0 \mathrm{hr}$, (2) $12 \mathrm{hr}$, (3) $24 \mathrm{hr}$ at $0^{\circ} \mathrm{C}$. 


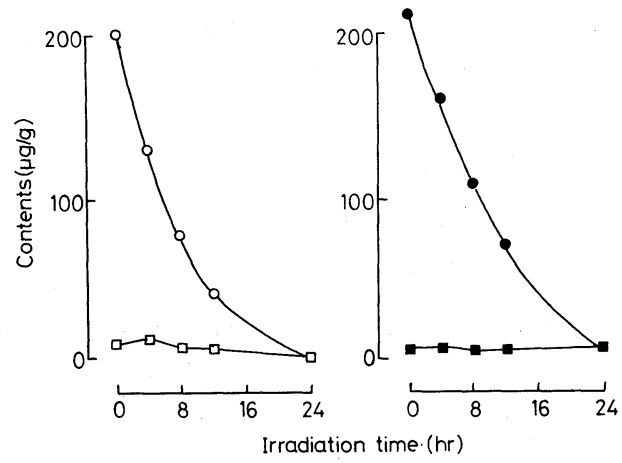

FIG. 3. Compositional Variation of Chlorophylls and Pheophytins in Methyl Linoleate during Photooxidation.

After chlorophylls $a$ or $b\left(2.2 \times 10^{-7} \mathrm{~mol}\right)$ was added to methyl linoleate $(1.0 \mathrm{~g})$ and photooxidized at $0^{\circ} \mathrm{C}$, contents of chlorophyll and pheophytin were estimated by the fluorometric method. $\bigcirc, \mathrm{Chl} a ; 0 ; \mathrm{Chl} b ; \square$, Phy $a$; Phy $b$.

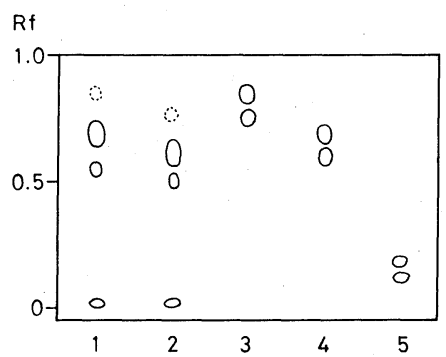

FIG. 4. Thin Layer Chromatogram of Photooxidation Products of Chlorophylls $a$ and $b$.

Plate, cellulose; solvent, $n$-heptane-pyridine (7:3); (1) Chl $a$ photooxidized for $12 \mathrm{hr}$; (2) $\mathrm{Chl} b$ photooxidized for $12 \mathrm{hr}$; (3) Phy $a$ and $b$; (4) Chl $a$ and $b$; (5) Pho $a$ and $b$.

or Pho was observed during photooxidation. The ratios of absorbance at the Soret band $\left(A_{\mathrm{s}}\right)$ to that at the Red band $\left(A_{\mathrm{I}}\right)$ of Chls $a$ and $b$ were estimated during photooxidation. ${ }^{19,20)}$ The ratio, $A_{\mathrm{S}} / A_{\mathrm{I}}$, in Chl $a$ after irradiation for 0,12 , and $24 \mathrm{hr}$ was $1.32,1.66$, and 3.72 , respectively. While the ratios in $\mathrm{Chl} b$ were $2.10,2.33$, and 2.67 , respectively. These results suggested that chelated magnesium might be removed from $\mathrm{Chl}$ during photooxidation. Next, variation in Phy content in ML was monitored by measurement of its fluorescence intensity during photooxidation of Chls. As shown in Fig. 3, Phys $a$ and $b$ were almost undetectable in contrast with the considerable decrease of Chl.
Thin layer chromatogram after photooxidation

Thin layer chromatograms of Chls $a$ and $b$ after photooxidation for $12 \mathrm{hr}$ are shown in Fig. 4. Four spots on the plate were observed in photooxidized $\mathrm{Chl} a$. The spot at $R f 0.68$ was in accord with the $R f$ value of Chl $a$ in the literature $^{17)}$ and other spots seemed to be photooxidation products of Chl $a$. Three spots with red fluorescence at $R f 0.84,0.53$, and 0 were grey-green, green, and red, respectively. The smallest spot at $R f 0.84$ was identified as Phy $a$ due to its $R f$ value and visible absorption spectrum. Visible absorption spectra of the other green spot $(R f 0.53)$ and the red spot $(R f$ $0)$ were shown in Table I. The green pigment exhibited absorption maxima at 415 and $662 \mathrm{~nm}$ in acetone, and its ratio of $A_{\mathrm{S}} / A_{\mathrm{I}}$ was 2.29. This suggested that no chelated magnesium exist in the molecule. On the other hand, the red pigment exhibited absorption maxima at 410 and $662 \mathrm{~nm}$ in acetone and the ratio of $A_{\mathrm{S}} / A_{\mathrm{I}}$ was 5.47 . Probably the red pigment also does not seem to possess a chelated magnesium. As photooxidation proceeded, the size of the red spot gradually increased, while the green spot disappeared.

Three spots were observed as the photooxidation products of $\mathrm{Chl} b(R f 0.62)$ as in the case of the photooxidized Chl $a$ (Fig. 4). Three spots with red fluorescence at $R f 0.76,0.50$, and 0 were green, yellow-green, and red, respectively. The spot at $R f 0.76$ was identified as Phy $b$ by its $R f$ value and visible absorption spectrum. Other two spots were pooled from the plate and their visible absorption spectra

Table I. Spectral Properties of Photooxidation Products of Chlorophylls in ACETONe

\begin{tabular}{lccc}
\hline \multicolumn{1}{c}{ Compound } & $\begin{array}{c}\lambda_{\max } \mathrm{nm} \\
\text { (Soret) }\end{array}$ & $\begin{array}{c}\lambda_{\max } \mathrm{nm} \\
\text { (Red) }\end{array}$ & $\begin{array}{c}A_{\mathrm{S}} / A_{\mathrm{I}} \\
\text { (Soret/Red) }\end{array}$ \\
\hline $\begin{array}{l}\text { Photooxidized Chl } a \\
\text { Rf } 0.53\end{array}$ & 415 & 662 & 2.29 \\
$\quad$ Rf 0 & 410 & 662 & 5.47 \\
Photooxidized Chl $b$ & & & \\
$\quad$ Rf 0.50 & 450 & 643 & 2.17 \\
Rf 0 & 455 & 643 & 3.47 \\
\hline
\end{tabular}


were monitored (Table I). The yellow-green pigment $(R f 0.50)$ exhibited absorption maxima at 450 and $643 \mathrm{~nm}$ in acetone and a $A_{\mathrm{S}} / A_{\mathrm{I}}$ ratio of 2.17, suggesting the presence of chelated magnesium. The polar red pigment $(R f 0)$ exhibited absorption maxima at 455 and $643 \mathrm{~nm}$ and the $A_{\mathrm{S}} / A_{\mathrm{I}}$ ratio was 3.47 . This red pigment increased with irradiation time as in the case of Chl $a$.

No Phy was detected by fluorometric estimation in spite of its detection by TLC, so we assumed that the $\mathrm{Chl}$ underwent oxidation other than photooxidation in the oil system, resulting in transformation to Phy during TLC or column chromatography. We actually found a greater amount of Phy on the plate when the TLC of Chl was carried out in a chamber full of air. Accordingly the Phy observed on TLC under $\mathrm{N}_{2}$ is not expected to be a photooxidation product of $\mathrm{Chl}$ in ML.

The spots of Pho and chlorophyllide were not detected in photooxidized $\mathrm{Chl}$. This might be caused by the absence of chlorophyllase that catalyzes the transformation of $\mathrm{Chl}$ to chlorophyllide and the no acidic circumstance that transforms Chl to Phy and Pho.

\section{Prooxidant activity of photooxidation products}

Peroxide values of ML to which the photooxidation products of $\mathrm{Chl}$ were added were determined after photooxidation for 12 and $24 \mathrm{hr}$. As shown in Table II, photooxidation products of Chls also exhibited prooxidant effects.

Chl and Phy were photooxidized in a ML system as a model compound of oils. The photooxidative reaction of $\mathrm{Chl}$ obeyed firstorder kinetics and the reaction rate of Chl $a$ was higher than that of $\mathrm{Chl} b$. On the other hand, Phy was insensitive to oxygen and was hardly decomposed at all during irradiation. Huff $^{21)}$ showed that Chl $a$ in potassium phosphate buffer was more easily decomposed than $\mathrm{Chl} b$, and that Phy hardly reacted with oxygen when $\mathrm{Chl}$ and Phy were bleached in the presence of peroxides.

Ishitani and Kimura ${ }^{8)}$ reported that relative stabilities of Chls $a$ and $b$ and Phys $a$ and $b$
TABle II. EfFects of Photooxidized ChLOROPHYLLS ON PHOTOOXIDATION of Methyl LinOleate

The pigment (OD 1.0 at 662 or $643 \mathrm{~nm}$ ) was added to methyl linoleate $(1.0 \mathrm{~g})$ and photooxidized under the conditions described in METHODS.

\begin{tabular}{lcc}
\hline \multirow{2}{*}{ Sample } & \multicolumn{2}{c}{ POV (meq $/ \mathrm{kg})$} \\
\cline { 2 - 3 } & $12 \mathrm{hr}$ & $24 \mathrm{hr}$ \\
\hline Control & 42 & 123 \\
Photooxidized Chl $a$ & & \\
$\quad$ Rf 0.53 & 198 & 472 \\
Rf 0 & 201 & 467 \\
Photooxidized Chl $b$ & & \\
Rf 0.50 & 85 & 222 \\
Rf 0 & 80 & 227 \\
\hline
\end{tabular}

depend on the polarity of the solvent. We also observed a high stability of Chl $a$ in comparison with that of $\mathrm{Chl} b$ during photooxidation of triglycerides ${ }^{22}$ in contrast to the result in ML. Moreover, in our previous paper $^{23)}$ a relatively constant compositional ratio of the four pigments was observed in refined plant edible oils. Thus, from the practical view point it is of little significance to consider the $a$ - and $b$-types of $\mathrm{Chl}$ or Phy separately. The concentration and photooxidative behavior of $\mathrm{Chl}$ and Phy in ML were discussed in our other paper. ${ }^{4)}$

The qualitative analysis of photooxidation products of $\mathrm{Chl}$ indicated that neither Phy nor Pho was formed during the photooxidation of Chl, agreeing with the result reported by Jen et al. ${ }^{9)}$ However, our other paper ${ }^{23)}$ revealed that most plant edible oils contain higher amounts of Phy than Chl and that Phy is not transformed from Chl during oil-refining. This Phy may be transferred from plant materials in which Phy has been produced from $\mathrm{Chl}$ enzymatically or nonenzymatically.

Of the two spots observed on TLC, the green pigment seemed to be one of the allomerization compounds of $\mathrm{Chl}$ indicated by Hynninen et al. ${ }^{10,11,19)}$ and Strain. ${ }^{24)}$ But the visible absorption spectrum of this pigment did not coincide with the reported ones. The characteristics of another polar red pigment 
have been studied by Mackinney and coworkers, ${ }^{25,26)}$ but its detailed structure has not been clarified. We found that these photooxidation products of $\mathrm{Chl}$ could promote the oxidation of oils. It is possible that these photooxidation and decomposition products may exist in some plant oils. Thus the structure and contents of $\mathrm{Chl}$ decomposition products in oils should be further investigated to determine the quality of the oils.

\section{REFERENCES}

1) J. Terao and S. Matsushita, Agric. Biol. Chem., 41, 2467 (1977).

2) E. N. Frankel, W. E. Neff and T. R. Bessler, Lipids, 14, 961 (1979).

3) R. Usuki, T. Suzuki and T. Kaneda, Yukagaku, 32, 321 (1983).

4) Y. Endo, R. Usuki and T. Kaneda, J. Am. Oil Chem. Soc., in press.

5) J. G. Johnston and W. F. Watson, J. Chem. Soc., 1203 (1956).

6) C. T. Tan and F. J. Francis, J. Food Sci., 27, 232 (1962).

7) Y. Mori, T. Naeda, Y. Ikeda and N. Matsumoto, Eiyô to Syokuryô, 22, 115 (1969).

8) T. Ishitani and S. Kimura, Nippon Syokuhin Kôgyô Gakkaishi, 24, 448 (1977).

9) J. J. Jen and G. Mackinney, Photochem. Photobiol., 11, 297 (1970).
10) P. H. Hynninen, S. Assandri, Acta Chem. Scand., 27, 1478 (1973).

11) P. H. Hynninen, Acta Chem. Scand., 27, 1487 (1973).

12) F. A. Lee and, A. C. Wagenknecht, Food Res., 23, 584 (1958).

13) A. H. Jackson, "Chemistry and Biochemistry of Plant Pigments," Vol. I, ed. by T. W. Goodwin, Academic Press, London, New York, San Francisco, 1976, p. 788.

14) G. C. Walker, J. Food Sci., 29, 383 (1964).

15) Y. Sita Rama Sastry, P. V. Rao and G. Lakshminarayana, Oléagineux, 28, 467 (1973).

16) I. Bratkowska and H. Niewiadomski, Rocz. Technol. Chem. Zyw., 18, 69 (1970).

17) G. Sievers and P. H. Hynninen, J. Chromatogr., 134, 359 (1977).

18) D. G. Harris and F. P. Zscheile, Bot. Gaz., 104, 515 (1943).

19) P. H. Hynninen and N. Ellfolk, Acta Chem. Scand., 27, 1463 (1973).

20) H. J. Perkins and D. W. A. Roberts, Biochim. Biophys. Acta, 79, 20 (1964).

21) A. Huff, Phytochem., 21, 261 (1982).

22) R. Usuki, Y. Endo, and T. Kaneda, Agric. Biol. Chem., 48, 991 (1984).

23) R. Usuki, T. Suzuki, Y. Endo and T. Kaneda, J. Am. Oil Chem. Soc., in press.

24) H. H. Strain, Agric. Food Chem., 24, 1222 (1954).

25) J. J. Jen and G. Mackinney, Photochem. Photobiol., 11, 303 (1970).

26) M. M. Morris, Y. Park, G. Mackinney, J. Agric. Food Chem., 21, 277 (1973). 